\title{
Correction to: A recent colonizer bird as indicator of human-induced landscape change: Eurasian collared dove (Streptopelia decaocto) in a small Mediterranean island
}

\author{
Corrado Battisti $^{1,2}$ (D) Francesco Zullo ${ }^{3}$ \\ Published online: 30 August 2019 \\ (C) Springer-Verlag GmbH Germany, part of Springer Nature 2019
}

\section{Correction to: Regional Environmental Change https://doi.org/10.1007/s10113-019-01547-y}

The article which was recently published contained a minor error in Figure 1. The author incorrectly sent Figure 1, relating to another study (Carpobrotus not Streptopelia). The correct figure is given in this article.

Publisher's note Springer Nature remains neutral with regard to jurisdictional claims in published maps and institutional affiliations.

The online version of the original article can be found at https://oi.org/ 10.1007/s10113-019-01547-y

\footnotetext{
Corrado Battisti

c.battisti@ cittametropolitanaroma.gov.it

Francesco Zullo

francesco.zullo@univaq.it

1 “Torre Flavia” LTER (Long Term Ecological Research) Station, Città Metropolitana di Roma Capitale, Servizio Aree Protette, Via Tiburtina 691, 00159 Roma, Italy

2 Dipartimento di Scienze, Università degli Studi di Roma Tre, Viale Marconi 446, 00146 Rome, Italy

3 Department of Civil, Construction-Architectural and Environmental Engineering, University of L'Aquila, Via Giovanni Gronchi, 18, 67100 L'Aquila, Italy
} 


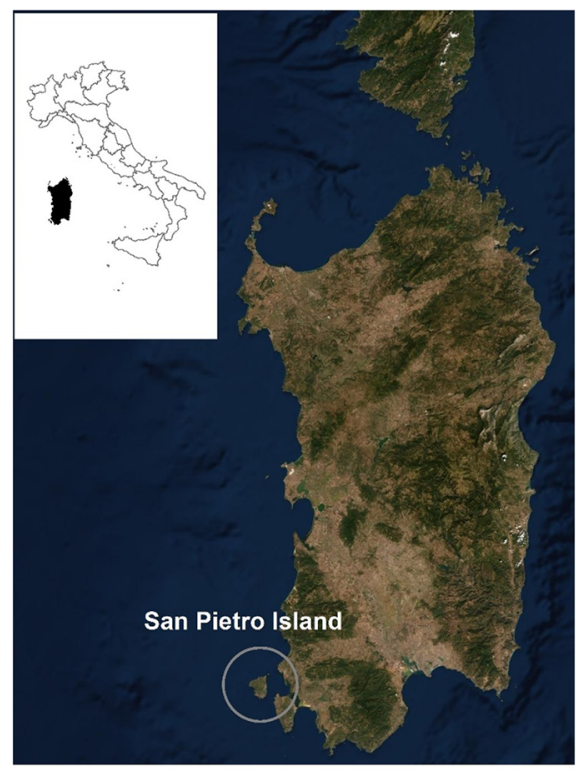

- Occurrence points of Streptopelia decaocto

Q Random points of Streptopelia decaocto

Paved roads with high traffic level

Pathways with low traffic level

San Pietro Island
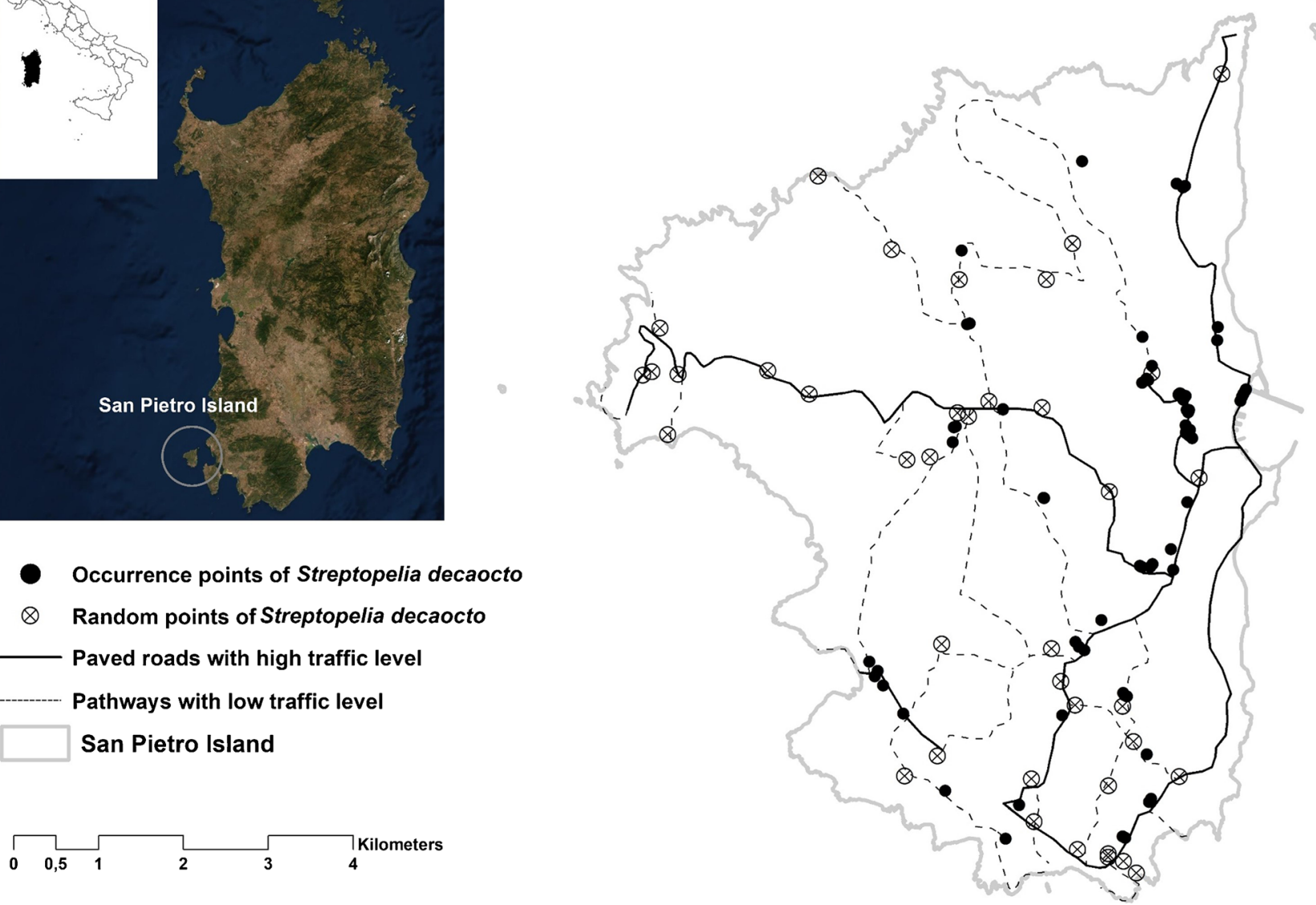

Fig. 1 Occurrence points (in black) and random (absence) points (circles with stars) of Streptopelia decaocto in the San Pietro Islands (South Sardinia) 